Original Article

\title{
ESTIMATION OF TOTAL PHENOL AND ANTIOXIDANT ACTIVITY OF ZANTHOXYLUM ARMATUM OF NEPALESE ORIGIN
}

\author{
DURGA DHAKAL, KHAGA RAJ SHARMA* \\ Central Department of Chemistry, Tribhuvan University, Kirtipur, Kathmandu, Nepal \\ Email: Khagaraj_sharma33@yahoo.com
}

Received: 15 Mar 2020, Revised and Accepted: 19 May 2020

\section{ABSTRACT}

Objective: The aim of this study was to analyze the phytoconstituents, estimation of total phenolic content and in vitro antioxidant activity of Zanthoxylum armatum from Myagdi district of Nepal.

Methods: The seeds extract of Zanthoxylum armatum was prepared by cold percolation in hexane, ethyl acetate and methanol with continuous agitation. Phytochemical analysis for each extracts was performed by color differentiation method adopting the standard protocol. Antioxidant potential of the extracts was performed by DPPH (2,2-diphenyl-1-picrylhydrazyl) free radical scavenging assay by taking ascorbic acid as standard. Total phenolic content was estimated by Folin-Ciocalteu reagent method.

Results: The analysis of secondary metabolites showed the presence of quinones and terpenoidsin almost all extracts while alkaloids, polyphenols, tannins and saponins were abundant in polar extracts. The results of antioxidant activity showed the methanol extract of Zanthoxylum armatum IC 50 $87.47 \mu \mathrm{g} / \mathrm{ml}$ was found to be more antioxidant as compared to the standard ascorbic acid IC $5066.40 \mu \mathrm{g} / \mathrm{ml}$. Ethyl acetate extract showed moderate antioxidant activity with IC $\mathrm{I}_{50} 142.04 \mu \mathrm{g} / \mathrm{ml}$, whereas hexane extract showed the poor antioxidant activity with IC $50384.03 \mu \mathrm{g} / \mathrm{ml}$. The result of total phenolic content showed, ethyl acetate fraction has the highest $26.28 \pm 9.35 \mathrm{mg} \mathrm{GAE} / \mathrm{g}$ as compared to methanol extract $23.36 \pm 14.80 \mathrm{mg}$ GAE$/ \mathrm{g}$ and hexane extract showed the poor phenolic content $20.05 \pm 8.0 \mathrm{mg} \mathrm{GAE} / \mathrm{g}$.

Conclusion: The seeds extracts of Zanthoxlum armatum were found the rich source of secondary metabolites. The methanol extract was found potent antioxidant as compared to ethyl acetate and hexane extract. It is concluded that further activity guided isolation approaches will be needed on methanol extract to identify the active compound responsible for in vivo and in vitro antioxidant activity.

Keywords: Zanthoxylum armatum, Phytochemicals, Antioxidant, Polyphenols, DPPH

(C) 2020 The Authors. Published by Innovare Academic Sciences Pvt Ltd. This is an open access article under the CC BY license (http://creativecommons.org/licenses/by/4.0/) DOI: http://dx.doi.org/10.22159/ijcpr.2020v12i4.39046. Journal homepage: https://innovareacademics.in/journals/index.php/ijcpr

\section{INTRODUCTION}

Human beings are using whole plants or the plant parts as medicine to cure the simple and life threating diseases from the time immemorial. Ancient literatures like Charaka and Sushruta in Ayurveda lists the major medicinal plants from the Indian subcontinent which was in practice for medication from different ethnic groups [1]. The use of natural products as medicines has been described throughout history in the form of traditional medicines, remedies, lotions and oils with many of these bioactive natural products still being unidentified. The major source of knowledge of natural product came due to the hit and trial uses of such natural sources as medicine and food since many years [2]. The biosynthesis and breakdown of proteins, fats, nucleic acids and carbohydrates, which are essential for the growth and development of living organisms is primary metabolism and the compounds involved in such mechanism are called primary metabolites. Secondary metabolites are formed by the biosynthesis in living organisms and these secondary metabolites impart the unique expression. Generally secondary metabolites do not play an important role in the growth, development and reproduction of an organism but play a significant role in adapting the living organisms to the surrounding environment acting as a possible defense mechanism against enemies to assist in the survival of the organism. Secondary metabolites as natural products results by the basic process of photosynthesis, glycolysis and Krebs cycle occurring in the living organisms [3, 4].

Zanthoxylum armatum, locally known as Boke Timur and Aankhe Timur, is a deciduous shrub or a small tree, around six meters tall or higher, with dense foliage, armed branched flattened prickles, yellow flowers and red seeds. Belonging to Rutaceae, it naturally occurs in Nepalese forests and on open sites at altitudes ranging from 1000 to 2100 meters and can be found in different management systems. As suggested by the peoples who are cultivating this plant, certain environments are better for grow, such as sites with deep, well-drained moist soils in full sun or semi-shade. This can explain the occurrence of Zanthoxylum armatum shrubs or small trees around cultivated crop fields [5].

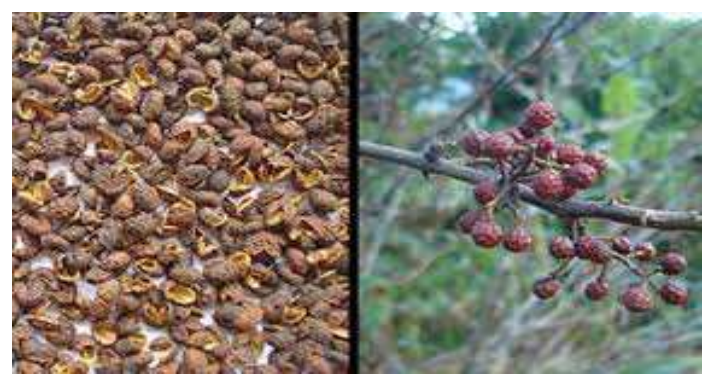

Fig. 1: Xantoxylumarmatum seeds 
Basically, the seeds and barks of Zanthoxylum armatum are highly used in indigenous system of medicine for the cure of carminative, stomachic and antihelmintic. The seeds are used as an aromatic tonic for fever and dyspepsia. The seed extract has been reported to be effective against roundworms. Lotion of seeds is used in scabies and in dental troubles. Chinese and Indian people have been reported to be using it on snake bites. The seeds taste great on addition in pickles making it a household preference in Nepalese kitchen [6].

Antioxidant is a chemical compound either synthesized or naturally isolated that inhibits the oxidation process happening in the body of living organisms. Oxidation is a chemical process that can generate free radicals that cause chain reactions and damage the body cells. Antioxidants are synthetic and natural and can terminate the chain reactions occurring in the body of living organisms [4]. Plants show a significant role in protecting human beings from various simple to life threating diseases. Due to this reason large number of peoples of the developing countries still rely on herbal medicines. Due to the excessive use of allopathic drugs, drug-resistant bacteria and viruses has spread around the world, which needs the novel drugs derived from natural products. Generation of free radicals inside the body of humans is a major health issue due to the oxidative stress caused by such free radicals. Present study focused on the antioxidant activity of different fractions of Zanthoxylum armatum seeds extracts along with the determination of total phenolic content. This study will help for isolating the active natural antioxidant from Zanthoxylum armatum seeds with less side effects and high efficacy.

\section{MATERIALS AND METHODS}

\section{Chemicals and equipment}

All reagents and solvents used were of laboratory reagent grade from E. Merck and Qualigens chemical companies, India. Buchi RE111 rot vapor was used for the evaporation of solvents. WPA spectrophotometer supplied by Philip Harris Shenstone, England and Thermo Scientific spectrophotometer was used to measure the absorbance of the solutions.

\section{Collection and drying of plant materials}

The seeds of Zanthoxylum armatum were bought from the local markets at Indrachowk, Kathmandu, which was collected and carried from Myagdi district. Seeds were cleaned, shade dried and crushed into a fine powder.

\section{Preparation of plant extracts}

The powder was weighed in an amount of fifty gram and every sample powder were soaked in $250 \mathrm{ml}$ of solvents i.e. hexane, ethyl acetate and methanol with continuous agitation. The plant samples were filtered and concentrated with a rotatory evaporator below the boiling point of solvents. The semi-solid dry plant extracts were stored at $4{ }^{\circ} \mathrm{C}$ until to perform their phytochemical and biological activities.

\section{Phytochemical screening}

The main class of natural products present within the plant extract was performed by the color differentiation method adopting the standard protocol [7].

\section{Total phenol content}

The total Phenol content was estimated by using Folin-Ciocalteu reagent with gallic acid as a standard supported oxidation-reduction reaction. The protocol adopted for the estimation of total phenol content was Khan et al. (2018) [8]. TPC was expressed in milligram gallic acid equivalent per gram of dry weight (mg GAE/g) of seed extracts using the formula, $\mathrm{C}=\mathrm{cV} / \mathrm{M}$ where $\mathrm{C}$ corresponds to the total phenolic content,c to the concentration of gallic acid established from the calibration curve in $\mathrm{mg} / \mathrm{ml}, \mathrm{V}$ is the volume of extract in $\mathrm{ml}$ and $\mathrm{M}$ is the weight of plant extract.

\section{Antioxidant activity}

The ability of different polar and non-polar fractions of plant samples and essential oil to scavenge 1,1-diphenyl-2-picryl-hydrazyl (DPPH) free radicals was estimated as previously described by Jain et al. (2008) [9].

$$
\text { Radical scavenging } \left.(\%)=\left[\left(\mathrm{A}_{0}-\mathrm{A}_{1}\right) / \mathrm{A}_{0}\right) \times 100\right)
$$

Where $A_{o}$ is the absorbance due to control and $A_{1}$ is the absorbance due to seed extracts.

The $\left(\mathrm{IC}_{50}\right)$ indicated as the effective concentration of the sample that is required to scavenge $50 \%$ of the DPPH free radicals. IC $\mathrm{C}_{50}$ values were calculated using the dose inhibition curve in the linear range by plotting the extract concentration versus the corresponding scavenging effect. Firstly, $10 \mathrm{mg}$ of the plant extract was dissolved in $10 \mathrm{ml}$ methanol to get the stock solution of a concentration of $1 \mathrm{mg} / \mathrm{ml}$. Different concentrations of the extracts $(10,30,50,70,90$ and $110 \mu \mathrm{g} / \mathrm{ml})$ were prepared in triplets by dilution from the stock solutions and $0.5 \mathrm{ml}$ of $0.2 \mathrm{mmol} \mathrm{DPPH}$ solution was added to each concentration. The solutions were kept in the dark for $30 \mathrm{~min}$ and their absorbance was measured at 517 nm against methanol as a blank. Ascorbic acid of the same concentrations was prepared as a standard and its absorbance was also measured at $517 \mathrm{~nm}$. Calibration curve was developed from the standard ascorbic acid.

\section{RESULTS AND DISCUSSION}

\section{Phytochemical screening}

The presence and absence of secondary metabolites in a different fraction of Zanthoxylemarmatum fruit extract is shown in table 1.

Table 1: Phytochemical screening of Zanthoxylum armatum seeds

\begin{tabular}{llll}
\hline Compounds & Hexane extract & Ethyl acetate extract & Methanol extract \\
\hline Volatile oil & - & - & - \\
Alkaloids & - & + & + \\
Fatty acids & + & + & - \\
Carotenoids & + & + & - \\
Terpenoids & + & - & + \\
Saponins & - & + & + \\
Polyphenols & + & - & + \\
Quinones & + & - & - \\
Tanins & - & - & + \\
\hline
\end{tabular}

(+) presence (-) absence

Among the extracts, hexane extract showed the presence of fatty acids, carotenoids, quinones and terpenoids; ethyl acetate extract showed the presence of terpenoids, fatty acids, and quinones whereas, the methanolic extract showed the presence of terpenoids, polyphenols and quinones and alkaloids. The results of the phytochemical analysis showed the similarity with the results reported by the previous scholars [10].

\section{Total phenolic content}

The result of phenolic content is shown in table 2 . The total phenolic content of all fractions of seed extracts showed varied data ranging from $20.05 \pm 8.07$ to $26.28 \pm 9.35 \mathrm{mg} \mathrm{GAE} / \mathrm{g}$ in hexane and ethyl acetate fraction, respectively. The ethyl acetate fraction has the highest total phenolic content, followed by 
methanol and hexane fractions. The result showed the total phenolic content was found almost similar to the results, as reported earlier $269.5 \pm 0.5 \mathrm{mg}$ GAE/100 $\mathrm{g}$ of total phenolic content in the Eclipta alba [11].

Table 2: Total phenolic content of different fractions of seeds extracts

\begin{tabular}{lllll}
\hline Plant extracts & & TPC mg GAE/g & mean \pm SD \\
\hline Hexane & 29.26 & 16.26 & 14.63 & $20.05 \pm 8.01$ \\
Ethyl acetate & 35.77 & 26.01 & 17.07 & $26.28 \pm 9.35$ \\
Methanol & 6.96 & 27.4 & 35.74 & $23.36 \pm 14.80$ \\
\hline
\end{tabular}

\section{Antioxidant activity}

The antioxidant potential has the inverse relation with $\mathrm{IC}_{50}$ value, which can be calculated from the linear regression of the percent inhibition versus concentration of seeds extracts. Lower value of IC 50 indicates high antioxidant potential. All the calculations were done by adopting the procedure given by Jain et al. (2008) [9] taking ascorbic acid as standard. The results of percentage scavenging with concentrations for different fractions as hexane, ethyl acetate and methanol is shown in fig. 2.
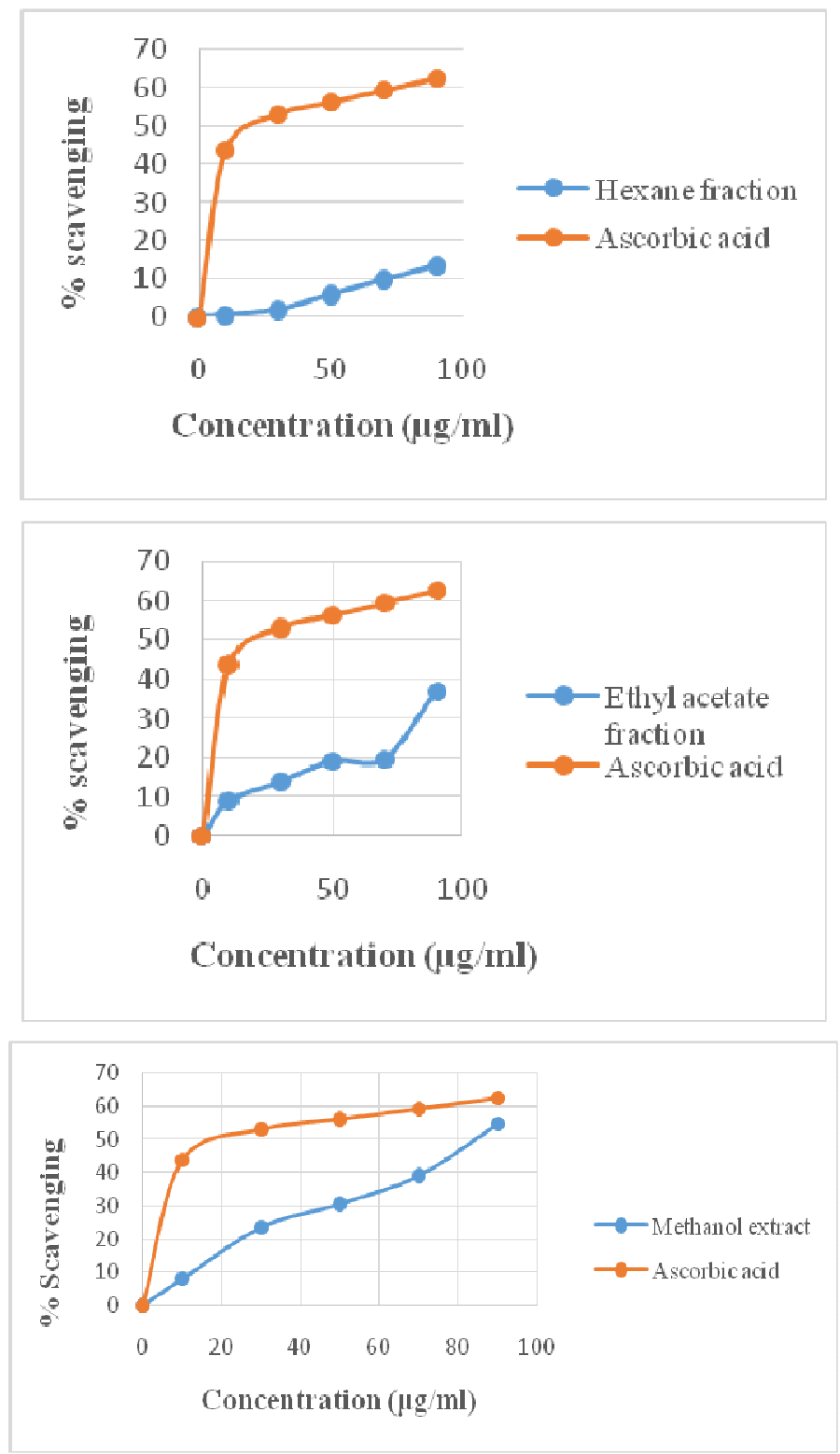

Fig. 2: Percent scavenging against the concentration of hexane, ethyl acetate and methanol extracts

Fig. 2 showed the concentration-dependent free radical scavenging activity of seeds extracts. The greatest radical scavenging potency with a minimum inhibitory concentration $\left(\mathrm{IC}_{50}\right)$ was shown for methanol fraction $87.47 \mu \mathrm{g} / \mathrm{ml}$ followed by ethyl acetate fraction
$142.04 \mu \mathrm{g} / \mathrm{ml}$ and hexane fraction $384.03 \mu \mathrm{g} / \mathrm{ml}$. The results were found nearly to that of the standard ascorbic acid $66.40 \mu \mathrm{g} / \mathrm{ml}$. The result of antioxidant activity in terms of inhibitory concentration is shown in table 3 . 
Table 3: Antioxidant activity of fractions of seeds extract expressed in $\mathrm{IC}_{50}$ values

\begin{tabular}{ll}
\hline Fractions of seeds extracts & Inhibitory concentration (IC) $\mathbf{5 0} / \mathbf{m l}$ \\
\hline Ascorbic acid & 66.40 \\
Ethyl acetate fraction & 142.04 \\
Hexane fraction & 384.03 \\
Methanol fraction & 87.47 \\
\hline
\end{tabular}

The results of antioxidant activity are found comparable with the results reported by the previous researchers. The results of radical scavenging potency with a minimum inhibitory concentration $\left(\mathrm{IC}_{50}\right)$ values were recorded for $S$. pinnata $(17.51 \pm 1.27 \mu \mathrm{g} / \mathrm{ml})$, followed by Bauhinia variegata $(26.55 \pm 2.61 \mu \mathrm{g} / \mathrm{ml}), \quad$ Melia azedarach $(62.04 \pm 1.55 \mu \mathrm{g} / \mathrm{ml})$, P. guajava $(70.91 \pm 2.61 \mu \mathrm{g} / \mathrm{ml})$, Curcuma longa $(83.50 \pm 6.42 \mu \mathrm{g} / \mathrm{ml})$, and Elaeocarpus angustifolius Blume $(104.23 \pm 3.58 \mu \mathrm{g} / \mathrm{ml})$ [12]. The findings of this study showed methanol extract of Zanthoxylum armatum seeds may be the source of natural antioxidants.

\section{CONCLUSION}

From this study, it is concluded that the Zanthoxylum armatum seeds extracts were found the rich sources of secondary metabolites. The potential activity of the extracts is due to the presence of such secondary metabolites as phytoconstituents. Determination of phenolic content showed the extracts of the seeds of this plant are rich in phenolic content that gives the scientific validation for the seeds of the plant that has been used by the peoples since many years for the cure of different diseases. Ethyl acetate fraction showed the highest content of phenolic compounds as compared to the methanol and hexane fractions. Radical scavenging activity was found maximum with moderate phenolic content that supported the phenolic compounds enhanced the antioxidant activity. Methanol and ethyl acetate fractions of Zanthoxylum armatum seeds extracts are the source of substances possess the ability to protect the body from damage caused by oxidative stress. The replacement of synthetic antioxidants by the natural antioxidants with less side effects and high efficacy may be advantageous because of implications for human health.

In the present study, analysis of free radical scavenging activity and determination of phenolic content showed that Zanthoxylum armatum seeds may be the potential source of natural antioxidants. It is concluded that further activity guided isolation approaches will be needed on methanol extract to identify the active compound responsible for in vivo and in vitro antioxidant activity.

\section{ACKNOWLEDGEMENT}

Authors are thankful to the Central Department of Chemistry. Tribhuvan University for laboratory facilities. We are grateful to the Central Department of Botany, Tribhuvan University for the identification of plant.

\section{FUNDING}

\section{Nil}

\section{AUTHORS CONTRIBUTIONS}

Sharma et al. analyse the data and wrote the manuscript, whereas Durga Dhakal carried out the laboratory work. Both the authors read and approved the final manuscript.

\section{CONFLICTS OF INTERESTS}

The authors declare that they have no conflict of interest for publishing this research article.

\section{REFERENCES}

1. Pandey MM, Rastogi S, Rawat AKS. Indian, traditional ayurvedic system of medicine and nutritional supplementation. Evid Based Complement Alternat Med 2013;1-12. https://doi.org/10.1155/2013/376327

2. Kong JM, Goh NK, Chia LS, Chia TF. Recent advances in traditional plant drugs and orchids. Act Pharmacol Sinica 2003;24:7-21.

3. Dias DA, Urban S, Roessner U. A historical overview of natural products in drug discovery. Metabolites 2012;2:303-36.

4. Mbah1 CJ, Ifeoma C, Ndiamaka O, Okorie H. Antioxidants properties of natural and synthetic chemical compounds: therapeutic effects on biological system. Acta Sci Pharm Sci 2019;3:28-42.

5. Paul A, Kumar A, Singh G, Choudhary A. Medicinal, pharmaceutical and pharmacological properties of Zanthoxylum armatum: a review. J Pharmacogn Phytochem 2018;7:892-900.

6. Singh TP, Singh OM. Phytochemical and pharmacological profile of Zanthoxylum armatum DC. An overview. Indian J Nat Prod Resour 2011;2:275-85.

7. Pokhrel B, Raut S, Rijal S. Phytochemical screening, antimicrobial and antioxidant activity of Melia azedarach leaves in methanol. World J Pharm Pharm Sci 2015;4:156275.

8. Khan MS, Yusufzai SK, Rafatullah M, Sarjadi MS, Razlan M. Determination of total phenolic content, total flavonoid content and antioxidant activity of various organic crude extracts of Licuala Spinosa leaves from sabah, Malaysia. ASM Sci J 2018;11:53-8.

9. Jain A, Soni M, Deb L, Jain A, Rout S, Gupta V, et al. Antioxidant and hepatoprotective activity of ethanolic and aqueous extracts of Momordica dioica Roxb. leaves. J Ethnopharmacol 2008;115:61-6.

10. Ranawat LS, Patel J. Antioxidant and hepatoprotective activity of ethanolic extracts of bark of Zanthoxylum armatum DC. In paracetamol-induced hepatotoxicity. Int J Pharm Sci Drug Res 2013;5:120-4.

11. Yadav NK, Arya RK, Dev K, Sharma C, Hossain Z, Meena S, et al. Alcoholic extract of Eclipta alba shows in vitro antioxidant and anticancer activity without exhibiting toxicological effects. Oxid Med and Cell Longevity 2017;18. https://doi.org/10.1155/ 2017/9094641.

12. Kharel R, Sharma KR. Evaluation of antioxidant potential and quantitative estimation of phenolic and flavonoid content in some selected Nepalese medicinal plants. Asian J Pharm Clin Res 2020;13:124-8. 